\title{
Air flow influences on local climate: comparison of a regional climate model with observations over the United Kingdom
}

\author{
John R. Turnpenny ${ }^{*, * *}$, Jennifer F. Crossley, Mike Hulme*, Timothy J. Osborn
}

Climatic Research Unit, School of Environmental Sciences, University of East Anglia, Norwich NR4 7TJ, United Kingdom

\begin{abstract}
The relationships between synoptic-scale air flow variability and surface temperature and precipitation simulated by the Hadley Centre's HadRM2 regional climate model (RCM; horizontal resolution $50 \mathrm{~km}$ ) were compared with observed relationships for the UK. The aims of the work were to test how well HadRM2 replicated observed relationships between atmospheric circulation and surface climate at a daily scale and to compare the regional model's performance with the global climate model (GCM) within which the HadRM2 is nested (the HadCM2 GCM). Synoptic-scale air flow variability over the UK was measured on a daily time scale by 3 indices: geostrophic flow strength, vorticity and direction. The frequency distribution of these 3 UK air flow indices is well simulated by HadRM2 in most seasons, with significant differences most noticeable in winter vorticity (the model has a bias to cyclonic vorticity) and in spring flow direction. Although HadCM2 also produced a reasonable simulation of the major frequency distribution features, HadRM2 represents a significant improvement; in 8 of the 12 distributions the simulations were not significantly different from the observations. The relationship between temperature and air flow indices was very well simulated by HadRM2, representing a marked improvement over HadCM2. However, similar relationships for precipitation were slightly less accurate in the RCM than the GCM, the main feature being overestimation of precipitation totals by between 20 and $50 \%$ in all seasons in the 2 regions studied. This is possibly due to propagation of GCM biases through the RCM boundary conditions, and may be overcome by running HadRM2 using observed rather than GCM data for the boundary conditions. Overall, the results show that more confidence could be placed in future UK climate change scenarios generated using HadRM2 rather than HadCM2 alone.
\end{abstract}

KEY WORDS: UK climate - Synoptic circulation - Regional climate model $\cdot$ Model evaluation · HadRM2

Resale or republication not permitted without written consent of the publisher

\section{BACKGROUND}

Simulation of present and future climates is typically done using coupled ocean-atmosphere general circulation models (GCMs), which leave an area such as the UK represented by, at most, 4 grid boxes. The general circulation patterns from GCMs provide a reasonable

\footnotetext{
*Present address: Tyndall Centre for Climate Change Research, School of Environmental Sciences, University of East Anglia, Norwich NR4 7TJ, United Kingdom.

${ }^{* *}$ E-mail: j.turnpenny@uea.ac.uk
}

representation of large-scale climate, but it is necessary to produce simulations with greater resolution to represent the subtleties of the UK topography, land cover and ocean influence. There are several methods of 'downscaling' from GCMs to an increased spatial resolution, including deriving empirical regression relationships between GCM-scale features and local climate (Wilby \& Wigley 1997), or nesting limited-area dynamical/physical models within the GCM (Giorgi \& Mearns 1999). A regional climate model (RCM), with a typical horizontal resolution of 50 to $125 \mathrm{~km}$, can be used to 'downscale' the GCM data to provide more 
detailed simulations. Murphy (1999) found little difference in predictive skill between dynamical and empirical techniques in simulating current climates over Europe using the Hadley Centre's HadRM2 RCM, but the applicability of the empirical regression relationships under a changed climate is a major source of debate. Indeed, Murphy (2000) found a large spread in regional climate predictions between different downscaling methods based on the same GCM output.

A number of climate modelling groups have developed RCMs nested within (i.e. taking lateral boundary conditions from) GCMs which provide higher spatial resolution of the local topography within the GCM boxes. The Hadley Centre GCM (HadCM2, Johns et al. 1997) uses a nested RCM (Jones et al. 1995) with a $50 \mathrm{~km}$ resolution, as do the NCAR CCM2 and CCM3 models (Lynch et al. 1995, Leung \& Ghan 1999) and the ECHAM4 model (Rinke et al. 1999). The advantage of this dynamical approach is improved spatial detail in the model output, and increased confidence derived from use of the RCM's representation of physical processes rather than empirical relationships. However, RCMs are computationally expensive and, though having an improved representation of smaller-scale processes than GCMs, still exhibit systematic errors due to parameter uncertainties and the remaining unresolved sub-grid-scale processes.

\section{AIMS AND OBJECTIVES}

The most common methods of evaluating the performance of RCMs are to compute pattern correlations between observed and simulated fields (e.g. Wetzel \& Bates 1995, Leung \& Ghan 1999) and to compare simulated and observed data at specific sites using descriptive statistics (Renwick et al. 1998). Rinke et al. (1999) evaluated model performance by comparing simulated and observed temperature through the depth of the atmosphere. One way to cut down on computational expense is to use 'actual time verification', in which the models are integrated over a particular time period, driven using atmospheric observations for that period as boundary conditions, and compared with the observations for the period (e.g. Christensen et al. 1997). These 'perfect boundary condition' experiments avoid errors in the general circulation simulation being passed on to the RCM, and thus allow assessment of the RCM performance alone.

Another useful way to test the performance of a model is to compare simulated and observed values of quantities which are easy to measure, and for which long observed records already exist. Conway et al. (1996) developed a method of relating large-scale synoptic circulation characteristics to local weather condi- tions, which is useful in empirical downscaling of GCM output to the regional scale. The method relates air flow indices (AFI) - which measure the vorticity, strength and direction of the geostrophic flow field, computed from mean sea level pressure data - to regional temperature and precipitation. Osborn et al. (1999) used AFI to analyse the relationships between large-scale flow characteristics and UK temperature and precipitation in the HadCM2 GCM (Johns et al. 1997) and compared them with the observed relationships. Hence the reliability of certain aspects of the GCM performance were tested over a range of conditions and at the individual grid-box scale. The validation process assumes that relationships between large-scale flow and surface temperature and precipitation remain constant under a changed climate. It must be noted that this may not be the case. Other large-scale predictors could also be used, such as humidity at multiple levels in the atmosphere (e.g. Crane \& Hewitson 1998), cloud cover and atmospheric radiative properties. Again, it must be noted that the interactions of these predictors may also change under a future climate. The non-availability of daily specific humidity and geopotential height data for this HadRM2 simulation did not allow use of these predictors. Note that Murphy's (1999) analysis of HadRM2 reports that, while vorticity is a good predictor of precipitation, humidity at $850 \mathrm{mb}$ has limited skill in predicting precipitation in winter and even less in summer.

The work presented here follows from, and complements, the evaluation of the HadCM2 GCM (Osborn et al. 1999, referred to subsequently as O99), by carrying out a similar analysis of the HadRM2 regional climate model nested within HadCM2 positioned over Europe and evaluated for the UK. Fig. 1 shows the comparisons and relationships studied. A 'relationship' examines the links between different variables, such as AFI and temperature. A 'comparison' examines the differences between modelled and observed values of the same variables, or between relationships derived using modelled and observed values.

In summary, the aims of the work presented here are to (1) examine the ability of the RCM to replicate observed conditions and (2) compare the performance of the GCM and RCM over the UK.

This assessment therefore provides evidence for how credible climate change scenarios for the UK based on an RCM simulation may be. The next generation of national UK climate scenarios (cf. Hulme \& Jenkins 1998) are likely to be derived from RCM simulations.

\section{DESCRIPTION OF MODEL AND OBSERVATIONS}

The RCM nested within HadCM2 is described in Jones et al. (1995). It falls into the dynamical class of 


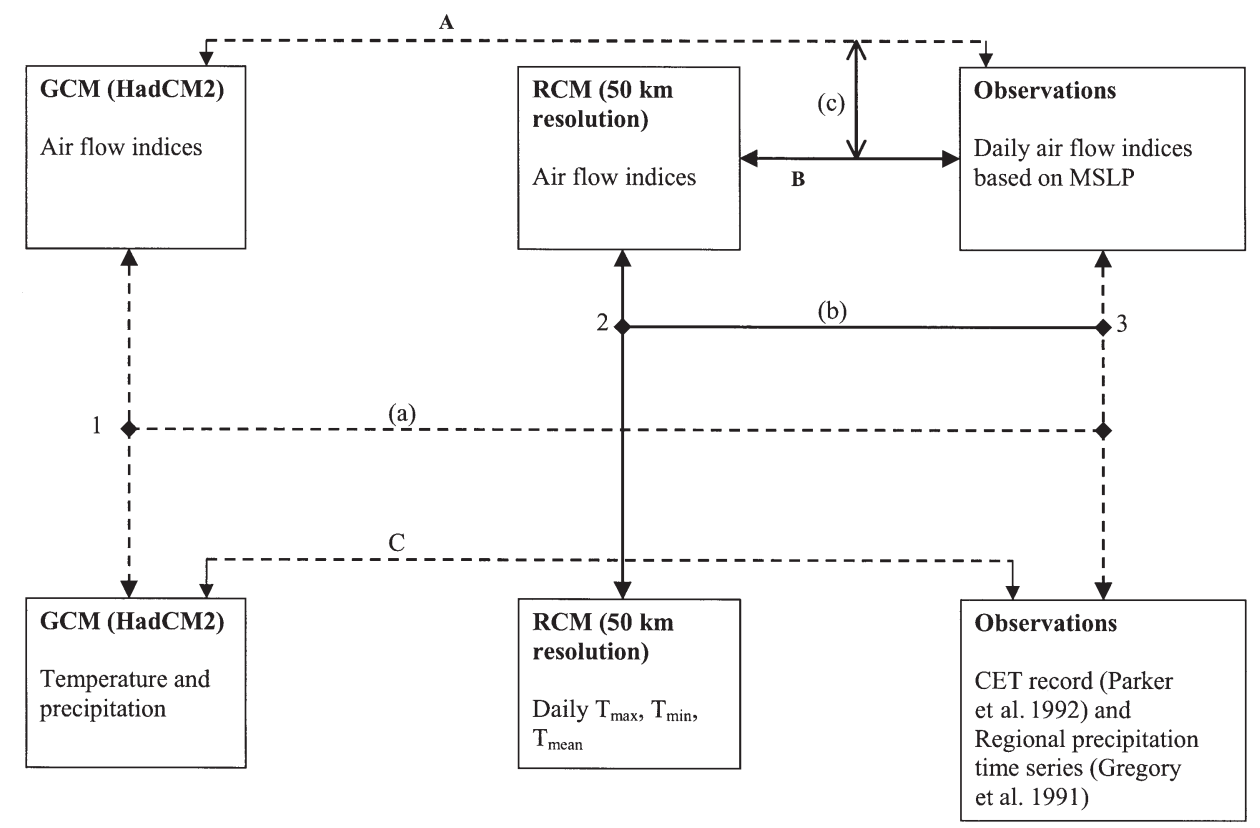

Fig. 1. Interrelationships between models and observations in the current study. A, B and C indicate comparisons; 1,2 and 3 indicate relationships; (a), (b) and (c) indicate comparisons of relationships. See text for further explanation. Dashed lines: work carried out by Osborn et al. (1999) (O99); solid lines: work presented in the current paper

downscaling methods, and as such it is computationally fairly expensive, with a horizontal resolution of $0.44^{\circ} \times 0.44^{\circ}$ (approximately $50 \mathrm{~km}$ ) and a time step of $5 \mathrm{~min}$. The orographic representation in HadRM2 is more realistic than in HadCM2 - for example, the elevations of the RCM boxes in northwest England and southern Scotland range from 83 to $340 \mathrm{~m}$, compared with a GCM mean of $135 \mathrm{~m}$ for the whole of this region. In reality the highest point in the region is $893 \mathrm{~m}$. The problem of converging lines of longitude with increasing latitude, which is significant over the UK, was solved by setting the location of the co-ordinate pole of the grid to $30^{\circ} \mathrm{N}, 160^{\circ} \mathrm{E}$, which forced virtually uniform resolution over Europe. For the simulations used here, the RCM was applied to the European region (approximately 35 to $70^{\circ} \mathrm{N}, 15^{\circ} \mathrm{W}$ to $60^{\circ} \mathrm{E}$ ). At its lateral boundaries, the RCM is driven by information (velocity, temperature and humidity) taken from the GCM. Near the lateral boundary, at each vertical level, the RCM value is adjusted by an increment dependent on the GCM value and the distance from the boundary; this 'relaxation zone' extends over a 4 grid-point GCMRCM boundary. The sea-surface temperature, sea ice cover and greenhouse-gas concentrations were also taken from the driving GCM. For this study, a $30 \mathrm{yr}$ control simulation from the RCM is used, driven by a 30 yr control run of HadCM2, with $\mathrm{CO}_{2}$ concentrations appropriate to the second half of the 20th century.

The observed data used for comparison were the 1881-1999 period of the daily Central England Tem- perature record (CET; Parker et al. 1992, since updated) and the 1931-1983 daily precipitation record for the 9 regions of the UK as defined by Gregory et al. (1991). These regions are: East Scotland (ES), Northwest and North Scotland (NS), Southwest and South Scotland (SS), Central and Eastern England (CE), Northwest England and North Wales (NWE), Northeast England (NEE), Southeast England (SEE), Southwest England and South Wales (SWE) and Northern Ireland (NI). For temperature, the long-term mean seasonal cycle was removed by smoothing the observed and simulated daily time series with $21 \mathrm{~d}$ running means, and subtracting these smoothed 'seasonal cycles' from the respective daily series. Comparison of the resulting anomalies in the observed and RCM series allowed an assessment of the influence of airflow without including any bias in simulation of the seasonal cycle by the RCM. This procedure was not carried out for precipitation since the seasonal cycle is much less pronounced than for temperature in mid latitudes.

Fig. 2a shows the location of mean sea-level pressure (MSLP) points used to derive the observed AFI for the period 1881-1993, and the amalgamations of precipitation regions used in the 099 analysis. Additionally, all the regions and data sources are defined by 099. Fig. 2b shows the location of the HadCM2 grid boxes used in O99. This should be compared with the map of HadRM2 grid boxes (Fig. 3) used in the current work, which shows a marked improvement in the resolution 
of the UK. MSLP values from the HadRM2 grid boxes nearest to the points shown in Fig. 2a were used in the analysis. Hence the AFI were computed in the same way as for the observed MSLP, following the method
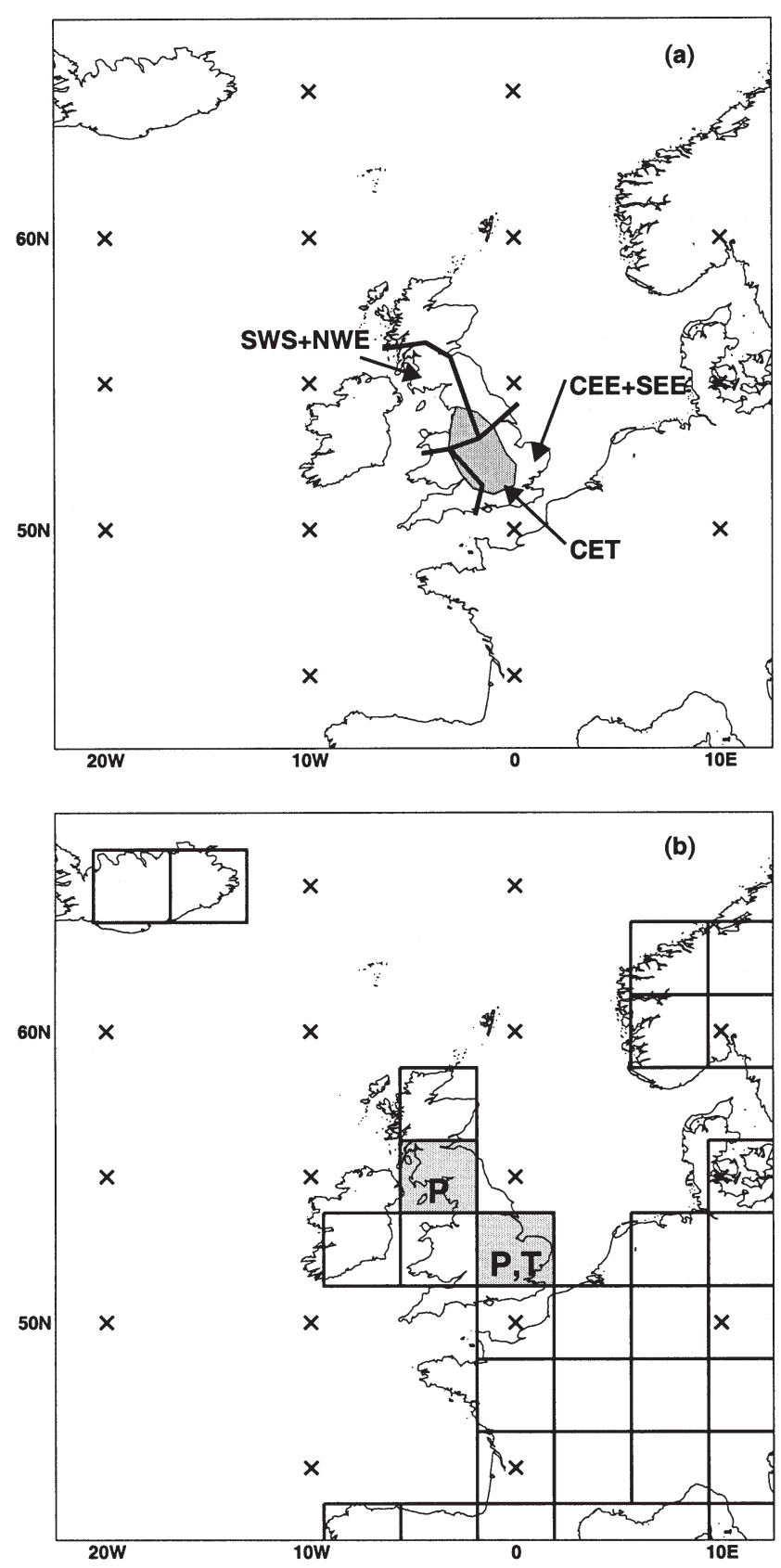

Fig. 2. (a) Location of sea-level pressure points $(x)$ used to compute air flow indices (AFI), and location of the region (shaded) for which the observed Central England Temperature (CET) is representative. The regions 'SWS + NWE' and 'CEE + SEE' are amalgamations of precipitation regions SS, NWE, CE and SEE used by O99. (b) Location of HadCM2 land grid boxes used by O99. The 2 boxes (shaded) are those from which simulated daily precipitation (P) was taken; simulated daily mean temperature was taken from box $\mathrm{T}$ described by Jones et al. (1993), which itself was based on the classification of circulation types by Jenkinson \& Collison (1977). The RCM series representing the CET region was obtained from an average of 26 appropriate RCM grid boxes, and the precipitation series for NWE and $\mathrm{CE}$ were derived from averages of 9 and 15 grid boxes respectively. These regions are indicated in Fig. 3.

\section{ANALYSES}

The work presented here consists of 3 parts:

(1) Comparison of the RCM-simulated frequency distributions of AFI with the observed distributions (comparison B in Fig. 1). This was done by classifying each observed and modelled value of flow strength, vorticity and flow direction into classes (defined in Table 1) and plotting frequency diagrams for each index. The size of each class was chosen so the full range of each index was represented by 20 classes, which ensured sufficient samples in each class for robust statistical analysis, while allowing representation of the detail of the relationships. The 4 standard climatological seasons were analysed separately: winter (DecemberFebruary); spring (March-May); summer (JuneAugust) and autumn (September-November).

(2) Analysis of the relationship between simulated surface temperature anomalies and the AFI (relationship 2 in Fig. 1), and comparison with the observed relationship [(b) in Fig. 1]. Each day was classified into the same classes as for part (1) and the mean temperature anomaly of all days that fall in a class was computed and plotted for each class.

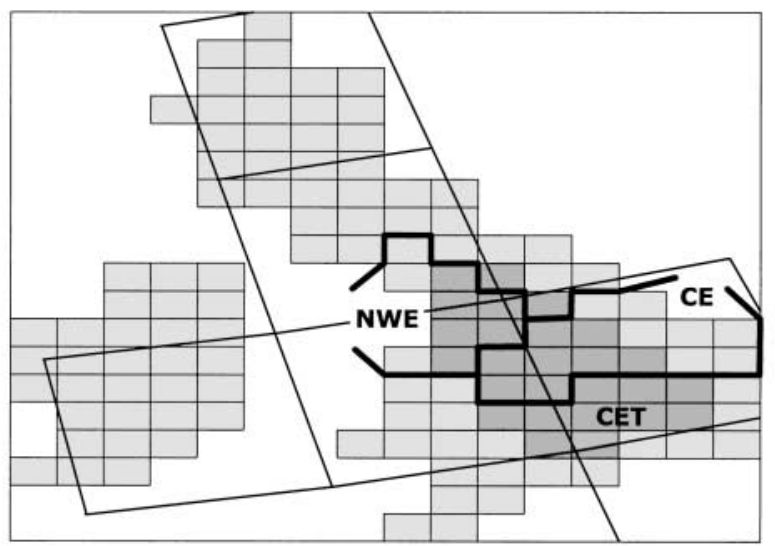

Fig. 3. Location of the 125 HadRM2 $50 \mathrm{~km} \times 50 \mathrm{~km}$ land grid boxes over the British Isles. The boxes corresponding to the precipitation and temperature regions used in the analysis are indicated, and the boxes corresponding to the CET region are shaded. Thin gridlines show the resolution of the land HadCM2 grid boxes 
Table 1. Classification of air flow indices (AFI)

\begin{tabular}{|lcll|}
\hline AFI & Class size & Units & Notes \\
\hline Strength & 2 & mb per $10^{\circ}$ latitude & At $55^{\circ} \mathrm{N} .1$ unit $=0.54 \mathrm{~m} \mathrm{~s}^{-1}$ \\
Vorticity & 6.5 & mb per $10^{\circ}$ latitude & At $55^{\circ}$ N. Negative vorticity $=$ anticyclonic circulation \\
Direction & $18^{\circ}$ & Degrees from north & $0^{\circ} / 360^{\circ}=$ northerly, $180^{\circ}=$ southerly \\
\hline
\end{tabular}

(3) The relationship between precipitation and the AFI (also relationship 2 in Fig. 1) and comparison with the observed relationship [(b) in Fig. 1] were analysed in the same way as for temperature. Dry days were included in the process of obtaining an average daily precipitation amount associated with each AFI class. Results from only 2 of the precipitation regions are presented in this paper: NWE and CE, to be approximately comparable with O99. However, O99 used averages of 2 regions (NWE/SS and CE/SEE) to obtain observed series representing areas similar to single GCM grid boxes.

\section{RESULTS}

\subsection{Simulation of air flow indices}

This analysis assessed the skill with which the RCM simulated the frequency of occurrence of the 3 different AFI during the 4 seasons (Fig. 4). The corresponding frequencies from HadCM2 (O99) are plotted as dotted lines for comparison. The grey shading about the observed data represents the zone within which the RCM simulation would be statistically indistinguishable from the observations (at the 90\% confidence level); it depends on the interannual variability and the number of observed and simulated values. Since the length of model simulation available with the RCM is shorter (30 yr) than that for the GCM (130 yr), the confidence intervals shown in Fig. 4 are generally a little broader than those obtained by O99. In general, the RCM does well in simulating UK air flow in most seasons, with significant differences most noticeable in winter vorticity and in spring flow direction. For flow strength the RCM is indistinguishable from observations in autumn, and in winter it only differs significantly in having too few days at the highest flow strengths. The RCM is a marked improvement over the GCM, which simulated too many moderate flow days at the expense of high flow days. In spring and summer there is a slight under-representation of weaker flow with a corresponding shift in the peak of flow strength towards stronger flow, with this effect exceeding confidence limits more clearly in summer. Similar to the GCM, the RCM underestimates the number of anti- cyclonic (negative vorticity) days and has a corresponding bias to cyclonic vorticity in all seasons, most marked in winter. This is probably due to a southward shift in the storm track simulated by HadCM2 with respect to observations (e.g. Johns et al. 1997). In the other seasons the differences between RCM and observations rarely exceed the confidence interval. For flow direction, model and observations are very similar in all seasons except spring, when the RCM fails to simulate the predominance of south to south-westerly flow. Once again, however, it is an improvement on the behaviour of the driving GCM, which also performed poorly during spring. Generally, it is interesting that the RCM improves on the driving GCM in the simulation of the air flow, even though the RCM domain was chosen to ensure that it basically reproduces the largescale circulation supplied by the driving model (e.g. Jones et al. 1995). This shows that the RCM can improve on the driving model at scales intermediate between the fine scales which are simply not resolved by the GCM, and the synoptic scales at which it is constrained to follow the GCM very closely.

\subsection{Influence of air flow on temperature}

The purpose of this part of the analysis was to establish relationships between the RCM AFI and the RCM mean daily surface temperature anomalies for the different seasons. The thick lines in Fig. 5 represent these relationships, with the thin lines denoting observed values, the dotted lines denoting the HadCM2 anomalies and the grey zone delimiting the area of $90 \%$ confidence for the RCM, as before. Some AFI values occur only rarely, and the classes have too few data points representing them for a statistically meaningful $90 \%$ confidence zone to be assigned to them; these are the areas around the thin lines in Fig. 5 where shading is absent. In addition, classes where there are fewer than 30 simulated values are not plotted; there are more such classes for the RCM than the GCM due to the shorter simulation length. Mostly these are incidences of very high flow strength (especially in summer) or extreme cyclonic vorticity, although flow directions between about 50 and $120^{\circ}$ also occur infrequently. 


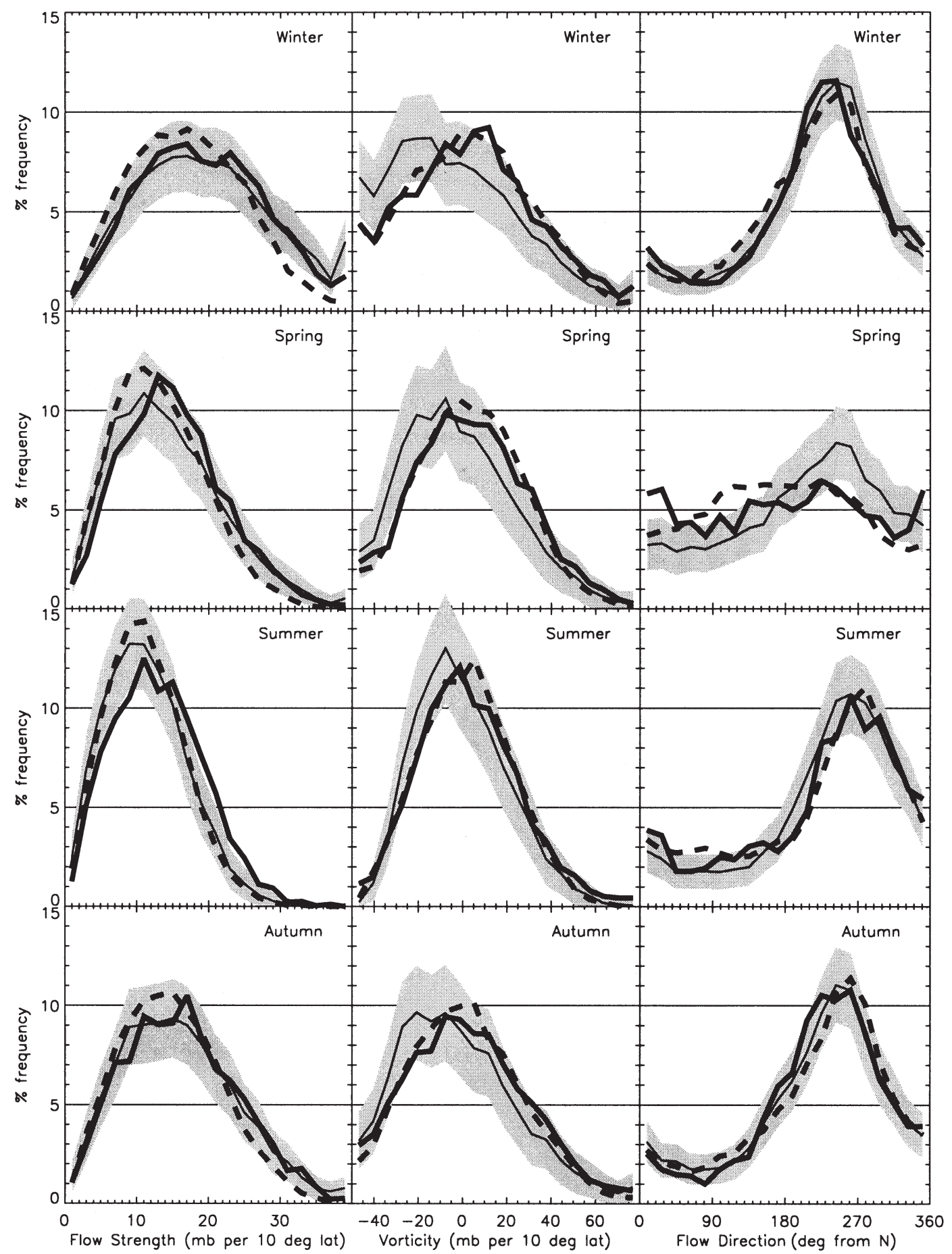

Fig. 4. Frequency with which daily AFI fall into particular bins on a seasonal basis. Each index is divided into 20 bins, with openended extreme bins. Thick line: HadRM2; thin line: observations; dotted line: HadCM2 (results from O99)

The RCM predicts a strong positive correlation between winter flow strength and temperature anomaly (i.e. stronger flow, milder temperatures), and between winter cyclonic circulation and temperature anomaly (i.e. more cyclonic, milder temperatures), which is as expected. In spring and autumn, the corresponding relationships are weaker than in the winter, but still positive. In summer, by contrast, there is a weak negative correlation between temperature anomalies and flow strength and cyclonicity. The 


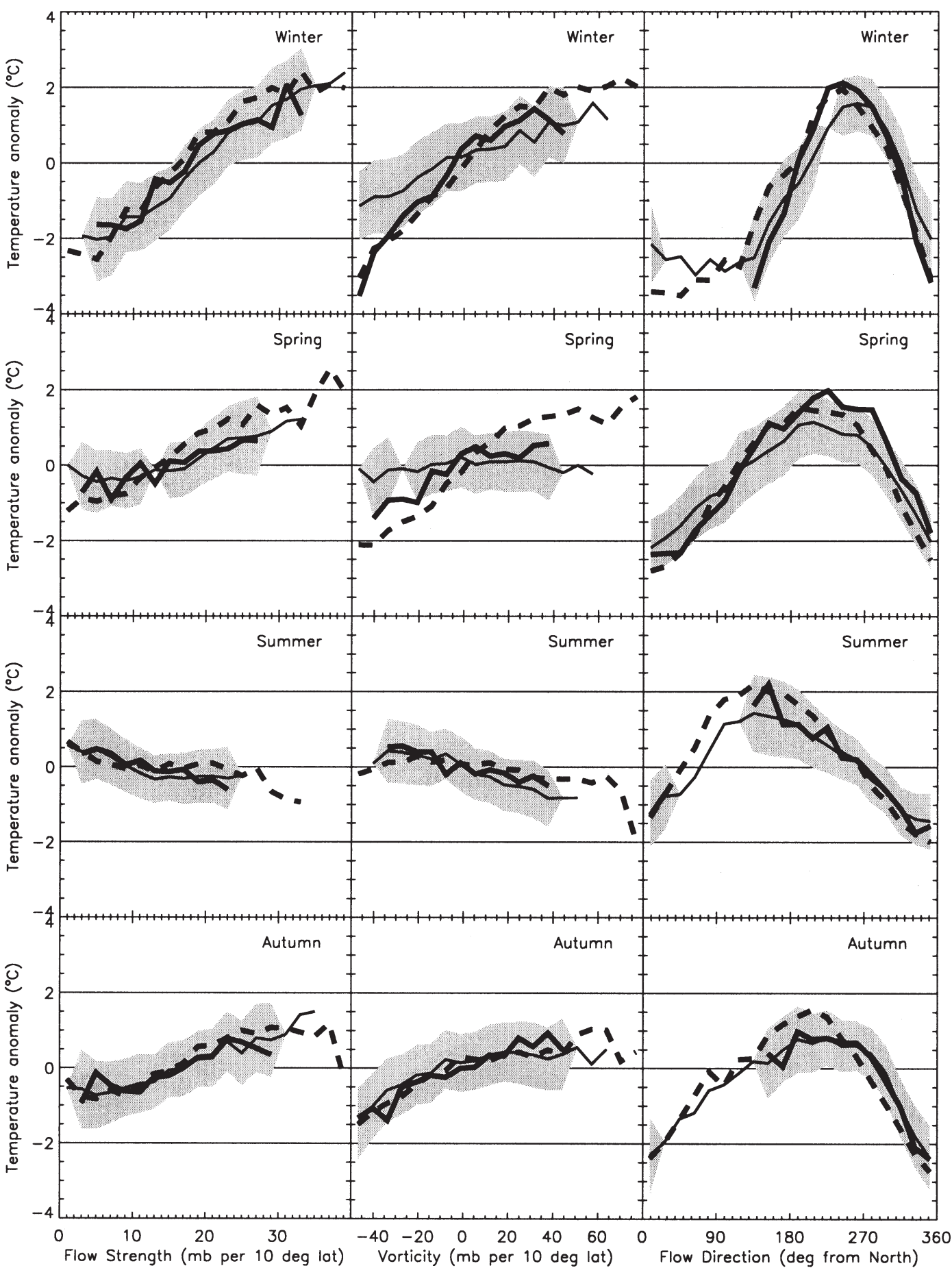

Fig. 5. Mean temperature anomaly of days whose AFI fall into particular bins, on a seasonal basis and for the 3 indices. Thick line: HadRM2; thin line: observations; dotted line: HadCM2. Only values computed from a sample of at least $30 \mathrm{~d}$ are shown

RCM successfully simulates this seasonal characteristic. Positive temperature anomalies in the summer result from calm anticyclonic conditions; the conditions which produce negative temperature anomalies in the winter. In winter, spring and autumn, the high- est temperatures are associated with south-westerly/ westerly flow $\left(+2^{\circ} \mathrm{C}\right.$ anomaly in winter and spring), but in summer, flow from the south-east across the warm European landmass brings the warmest temperatures. 
Generally the RCM produces a very good representation of observed conditions. In 10 of the 12 distributions the simulations match the observations within the $90 \%$ confidence limits. For all AFI and all seasons the general observed correlations between temperature anomaly and large-scale flow were reproduced. The only area of major discrepancy was that the RCM is much too cold during winter anticyclonic conditions: for example, an anomaly of $-3^{\circ} \mathrm{C}$ at a vorticity of -40 , in comparison with observed values around $-1^{\circ} \mathrm{C}$. This is likely to be due to the model underestimating cloud cover (Noguer et al. 1998), a known feature of the RCM's cloud parameterization scheme (Jones et al. 1995). In addition, the RCM tends to over-emphasise the warming effects of south-westerlies and cooling effects of south-easterlies in winter (by about $1^{\circ} \mathrm{C}$ ), so predicting a Central England climate where the temperature is more sensitive to wind direction than it is in reality.

Similar analyses were carried out for the anomalies in daily maximum and minimum temperatures. The main features of these results (not shown) were that predicted winter and spring minimum temperatures were even more over-sensitive to flow direction than the means, whereas the maximum temperatures are much better predicted. The winter minimum temperature is also more over-sensitive to vorticity than the mean. Observed anticyclonic conditions do not produce minima as low as the RCM suggests.

\subsection{Influence of air flow on precipitation}

It is important that the RCM correctly represents the regional variation in precipitation-circulation relationships, since precipitation varies more sharply with location than does temperature. The results for 2 regions of the UK are presented here-Central and Eastern England (denoted as CE) and Northwest England and North Wales (denoted as NWE) - to allow comparison with O99. Orography is more important in NWE than in CE, which is more uniformly flat. It is also important to note that the comparisons presented here refer to an average for the whole region-precipitation at individual locations within the regions can vary dramatically from the regional average, especially in the hillier NWE region.

For CE, Fig. 6 shows the relationships between daily precipitation totals as a function of the AFI for the 4 seasons for the RCM. The general patterns are picked up well by the RCM, even the weak dependence of precipitation total on flow strength and flow direction in all seasons and the small negative relationship with flow strength in the summer, when stronger winds produce marginally less rain. The noticeably weak depen- dence of precipitation on flow direction in CE is due to the rain shadow effect of the mountainous west, and this subtlety is picked up by the RCM. Precipitation increases with increasing positive (cyclonic) vorticity, as expected. The model has a tendency to over-predict precipitation totals in all seasons by between 22 (autumn) and $47 \%$ (winter), although in 10 of the 12 simulations the bias is within the $90 \%$ confidence limits. Further elaboration of this point appears in the following section.

The results of a similar analysis for NWE are given in Fig. 7. In the west there are much stronger relationships between precipitation and flow strength and cyclonicity, the pattern of which the RCM again picks up. However, there is more significant over-prediction of precipitation totals than in CE, especially in conditions of extreme cyclonic vorticity. Mean daily precipitation totals are over-predicted by between 15 (autumn) and $51 \%$ (spring); only in autumn does the $\mathrm{RCM}$ reproduce the observed distributions within the confidence limits. Under anticyclonic conditions, however, the RCM provides an excellent match with the observations in all seasons.

\section{COMPARISON OF HADRM2 AND HADCM2}

The next step in this analysis is to compare the current results with the O99 study to see whether the RCM improves on the GCM's simulations of surface climate variability over the UK. In terms of frequency distributions, the O99 study of HadCM2 found that only in summer flow strength did the model fall within the $90 \%$ confidence limits for all values (1 out of 12 distributions), whereas for the RCM 8 of the 12 model distributions were not significantly different from the observations (Fig. 4). We note, however, that the confidence ranges are somewhat wider here due to the smaller sample size of model output. The regional model therefore simulates the large-scale air flow over the UK better than HadCM2 for most indices and seasons: a significant success given the reliance of the RCM on the GCM boundary conditions in simulating synoptic-scale features. Indeed, Christensen et al. (1997) note that the increase in resolution in an RCM can sometimes actually worsen the biases in large-scale features which are output from GCM. Giorgi \& Mearns (1999) emphasise that when an RCM is forced by the boundary conditions of a GCM, both model types produce similar representations of large-scale features. The differences between the GCM and the RCM arise from the enhanced topographic resolution in the RCM, and in this study we are therefore testing this aspect of the RCM; hence the need to ensure that the comparisons are done with special attention to the locations. 


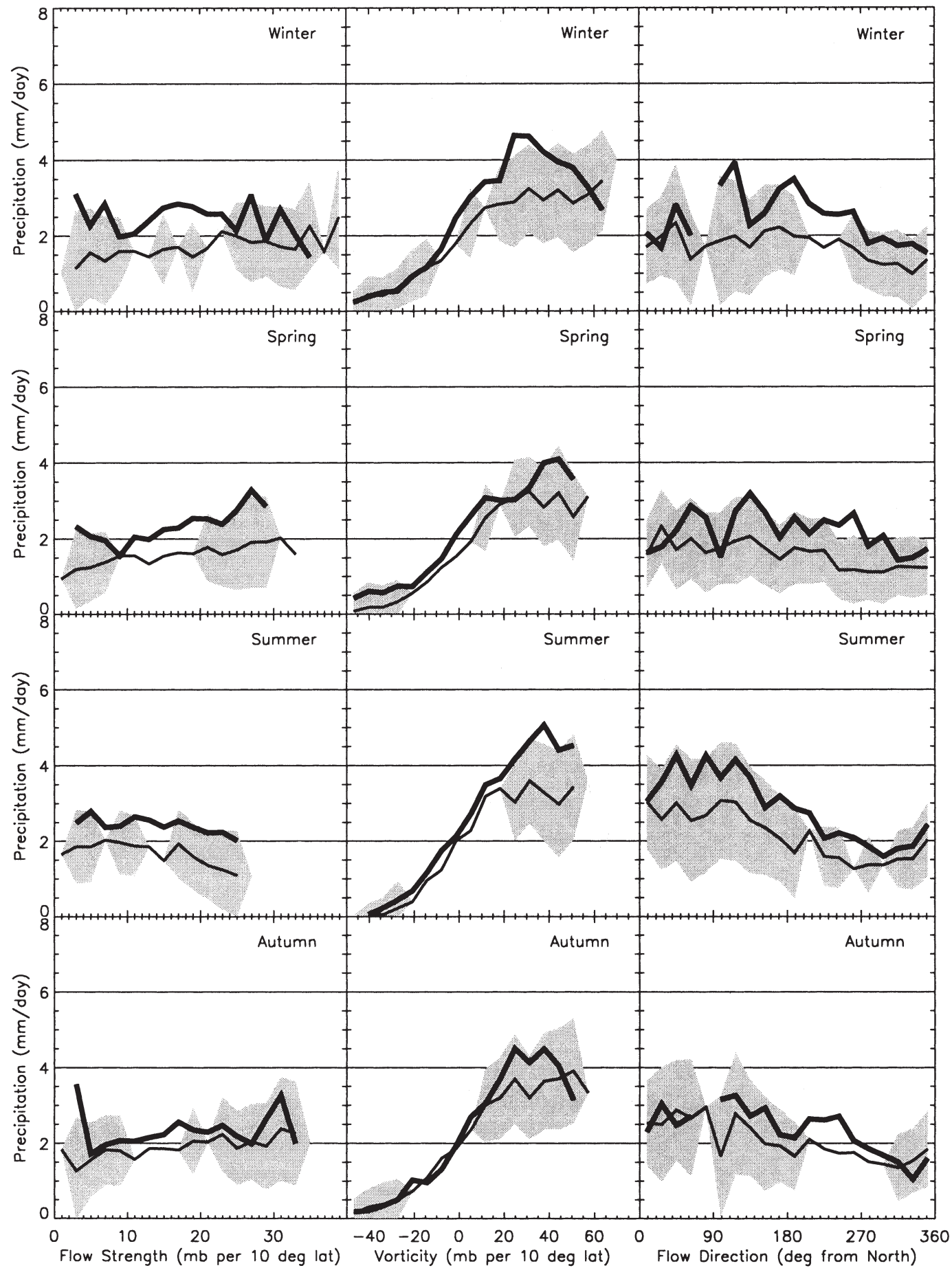

Fig. 6. Central and Eastern England (CE) mean precipitation of days whose AFI fall into particular bins, on a seasonal basis and for the 3 indices. Thick line: HadRM2; thin line: observations. Only values computed from a sample of at least $30 \mathrm{~d}$ are shown

For temperature, the RCM represents a marked improvement over the GCM alone (Fig. 5). In only 3 of the 12 GCM distributions were the observed relationships matched within $90 \%$ confidence limits: summer flow strength, autumn flow strength and autumn vorticity, all of which are fairly weak relationships. The RCM correctly estimates the magnitude of the temperature anomaly under winter cyclonic conditions, which the GCM overestimated by about $1^{\circ} \mathrm{C}$. The RCM also improves markedly in 


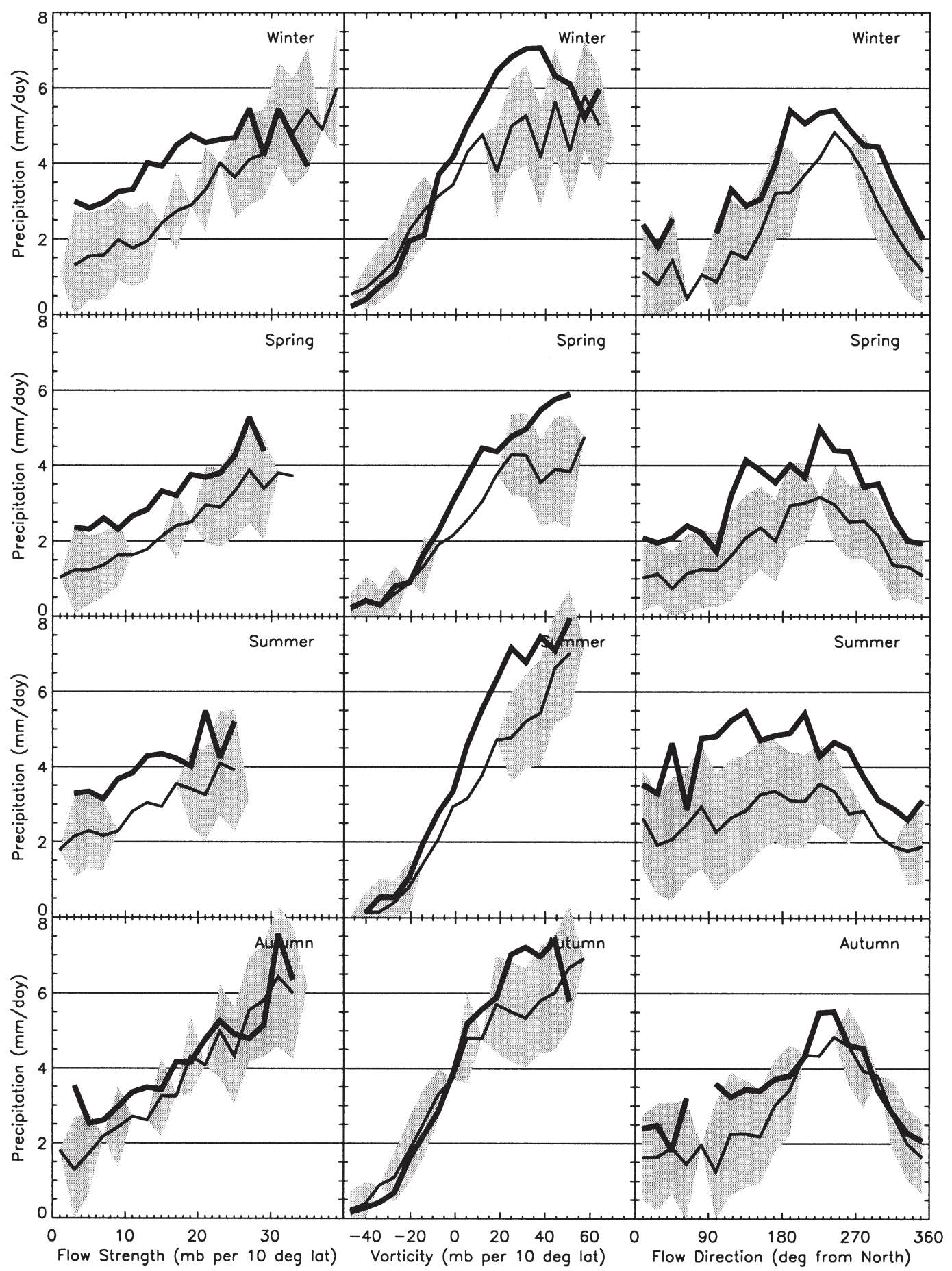

Fig. 7. Northwest England and North Wales (NWE) mean precipitation of days whose AFI fall into particular bins, on a seasonal basis and for the 3 indices. Thick line: HadRM2; thin line: observations. Only values computed from a sample of at least $30 \mathrm{~d}$ are shown

simulation of the relationship between temperature anomaly and flow strength in winter and spring, and the flow direction/temperature anomaly relationship in summer and autumn. Generally, the other combinations of season and AFI with temperature are simu- lated by the RCM within the confidence limits, where a typical GCM simulation (e.g. winter flow strength) would only simulate about $50 \%$ of the range of flow strength within the limits, and those mostly at the extremes of flow strength. 
For precipitation, however, the GCM's simulations are all slightly better than those of the RCM. This is, however, mainly due to the RCM's mean precipitation being too high in most seasons and both regions. In the $\mathrm{CE}$ precipitation region, the observations used in the GCM study are an average of the CE and SEE precipitation regions (Fig. 2a), since this corresponds more nearly to a whole GCM grid box. However, the differences encountered by adding in the SEE region are likely to be small. For this region, the main improvement of the RCM over the GCM is that precipitation on autumn or winter days with high positive vorticity is no longer underestimated (compare Fig. 6 with Fig. 8).

For the NWE area, the inter-model comparisons are less valid, since O99 refers to the NWE and SS HadCM2 grid box, whereas the current work examines the NWE regional precipitation. There are significant differences in topography between the 2 areas; nevertheless, the comparison is a useful exercise. It is for this reason that the GCM and RCM precipitation simulations are plotted on separate graphs (Figs 6-9). The RCM overestimates precipitation at all but the most anticyclonic vorticities, compared to the GCM which significantly underestimated precipitation at high cyclonic vorticities (compare Fig. 7 with Fig. 9). The RCM also over-enhances precipitation during westerly regimes, compared to the GCM, which underestimates this feature.

Table 2 shows the mean daily precipitation simulated by the GCM and RCM for the 4 seasons and both regions, highlighting the enhanced precipitation in the RCM. It confirms that the GCM simulations for NWE are too dry, underestimating daily totals by an average of $12 \%$. Conversely, the GCM is too wet in $\mathrm{CE}$, overestimating totals by about $25 \%$. However, the RCM is much wetter (20 to $50 \%$ ) in both regions and all seasons. A comparison between HadRM2 output and observed station data, rather than regional averages (Phil Reid pers. comm.), showed similar magnitudes of overestimation. East Anglia, northwest England, North Wales and upland areas of Scotland seem to be most prone to overestimation. Conversely, Murphy (1999, 2000), comparing HadRM2 with station observations, found that the model underestimated the frequency of dry days and intense precipitation events; however, Durman et al. (2001) found that the RCM overestimates the frequency of intense events when the model and observation data are aggregated to form spatial means corresponding to GCM grid boxes. This is due to the positive bias in precipitation highlighted in Table 2. There are several physical reasons why the GCM and RCM behave differently. The RCM has a stronger hydrological cycle than the GCM due to stronger vertical motions, itself a dynamical effect of higher resolution (Jones et al. 1995). Hence precipitation in the RCM will be overestimated unless the sub-grid scale physics is retuned in the RCM relative to the GCM (Noguer et al. 1998). This was not done for HadRM2 but explicit scale dependencies have been introduced in subsequent RCMs to optimise model performance. The bias is also enhanced by the GCM boundary conditions being too moist, and by other related biases with respect to observations. When the RCM is driven with observed winds and temperatures as boundary conditions, thus removing the influence of any biases in HadCM2, the errors are reduced in summer and winter (Noguer et al. 1998). One problem with using observed data as boundary conditions is the paucity of reliable and comprehensive observations - an example being the gaps in measurements of tropospheric moisture.

Table 2. Mean daily precipitation $\left(\mathrm{mm} \mathrm{d}^{-1}\right)$ for different seasons and regions: comparison between HadCM2 and HadRM2. Relative error $=$ simulated value/observed value. $\mathrm{DJF}=$ winter, $\mathrm{MAM}=$ spring, $\mathrm{JJA}=$ summer, $\mathrm{SON}=$ autumn

\begin{tabular}{|c|c|c|c|c|c|}
\hline Region & Model/Data set & DJF & MAM & JJA & SON \\
\hline $\mathrm{CE}$ and SEE & $\begin{array}{l}\text { HadCM2 } \\
\text { Observations } \\
\text { Relative error }\end{array}$ & $\begin{array}{l}2.33 \\
1.85 \\
1.26\end{array}$ & $\begin{array}{l}1.95 \\
1.57 \\
1.24\end{array}$ & $\begin{array}{l}2.21 \\
1.79 \\
1.23\end{array}$ & $\begin{array}{l}1.89 \\
2.05 \\
0.92\end{array}$ \\
\hline NWE and SS & $\begin{array}{l}\text { HadCM2 } \\
\text { Observations } \\
\text { Relative error }\end{array}$ & $\begin{array}{l}2.98 \\
3.59 \\
0.83\end{array}$ & $\begin{array}{l}2.39 \\
2.50 \\
0.96\end{array}$ & $\begin{array}{l}2.90 \\
2.81 \\
1.03\end{array}$ & $\begin{array}{l}2.82 \\
4.11 \\
0.69\end{array}$ \\
\hline $\mathrm{CE}$ & $\begin{array}{l}\text { HadRM2 } \\
\text { Observations } \\
\text { Relative error }\end{array}$ & $\begin{array}{l}2.48 \\
1.69 \\
1.47\end{array}$ & $\begin{array}{l}2.19 \\
1.51 \\
1.45\end{array}$ & $\begin{array}{l}2.46 \\
1.80 \\
1.37\end{array}$ & $\begin{array}{l}2.26 \\
1.86 \\
1.22\end{array}$ \\
\hline NWE & $\begin{array}{l}\text { HadRM2 } \\
\text { Observations } \\
\text { Relative error }\end{array}$ & $\begin{array}{l}4.23 \\
3.07 \\
1.38\end{array}$ & $\begin{array}{l}3.17 \\
2.10 \\
1.51\end{array}$ & $\begin{array}{l}4.00 \\
2.71 \\
1.48\end{array}$ & $\begin{array}{l}3.98 \\
3.45 \\
1.15\end{array}$ \\
\hline
\end{tabular}




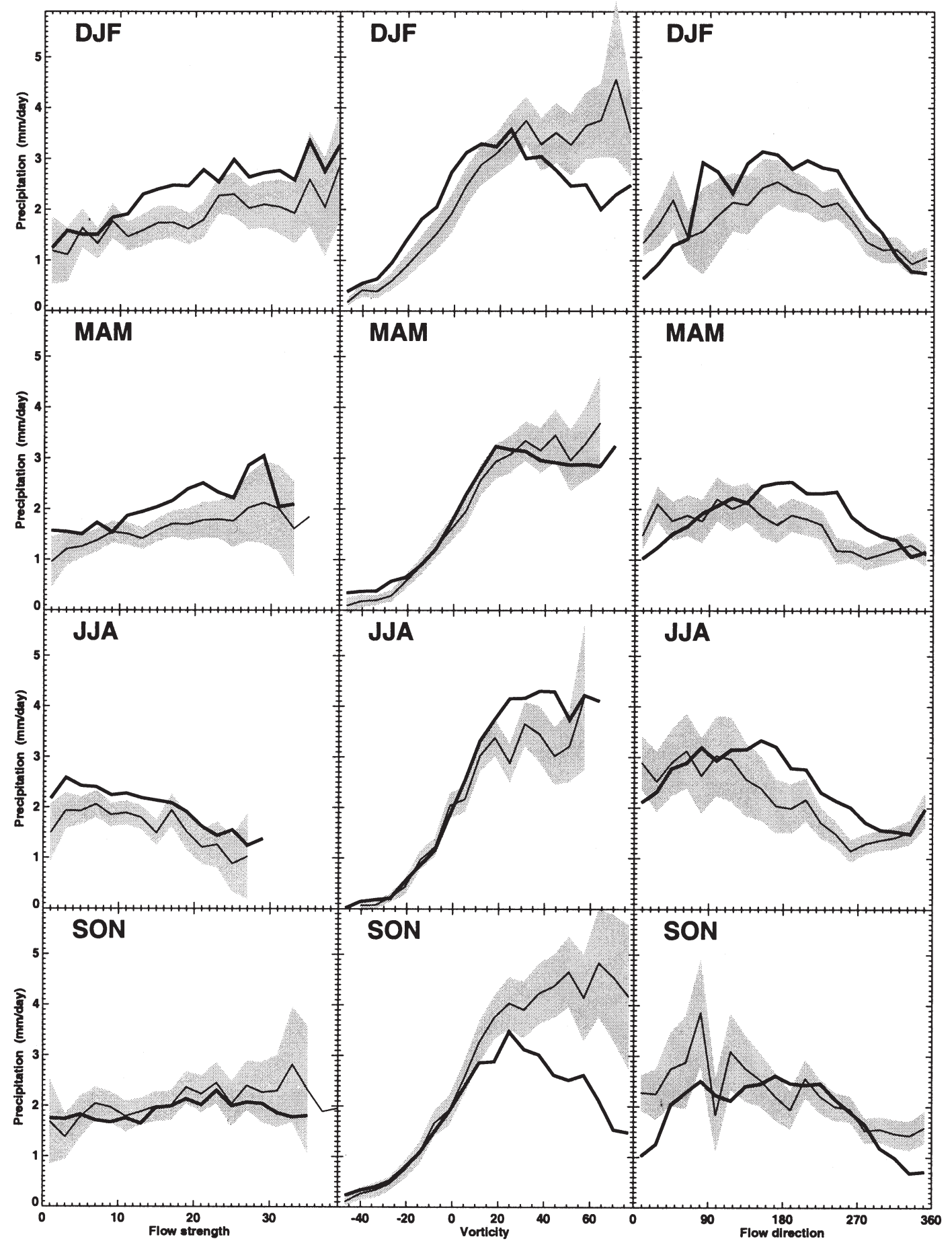

Fig. 8. As Fig. 6, but for HadCM2 (results from O99). Results are displayed for an amalgamation of the CE and SEE regions. DJF = winter, $\mathrm{MAM}=$ spring, $\mathrm{JJA}=$ summer, $\mathrm{SON}=$ autumn

\section{SUMMARY}

The Hadley Centre regional climate model, HadRM2, generally simulates the relationship between Central England temperature and air flow indices well, but does less well at predicting the magnitude of daily precipitation totals on the basis of air flow, largely because of a positive bias in mean precipitation. Giorgi \& Mearns (1999) found that regional models driven by observations rather than by GCM 


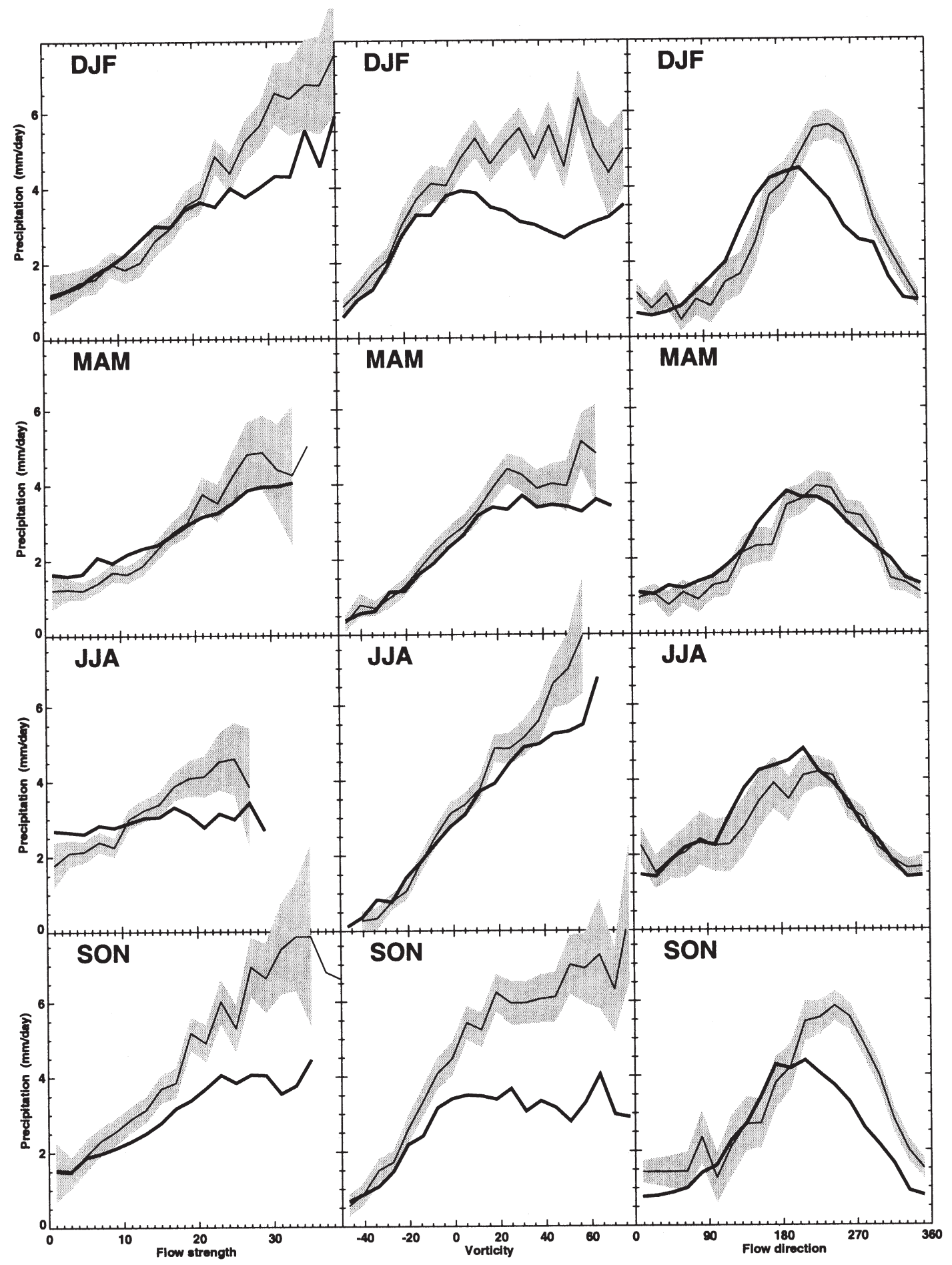

Fig. 9. As Fig. 7, but for HadCM2 (results from O99). Results are displayed for an amalgamation of the NWE and SS regions

boundary conditions can reproduce precipitation at the regional and seasonal scale in the ranges $\pm 5-30 \%$ and $\pm 0.5-2^{\circ} \mathrm{C}$. HadRM2, driven by the HadCM2 GCM, simulates temperature anomalies extremely well (better than $\pm 0.5^{\circ} \mathrm{C}$ ) and the precipitation simulations are mostly within $30 \%$ of the observed values. If the
RCM's overestimation of precipitation is ignored, the general shape and position of the precipitation-circulation relationships shows a number of improvements in the RCM compared to the GCM (compare Fig. 7 with Fig. 9). The RCM captures the strength of the relationship with flow strength much better, and the wettest 
flow direction is closer to that observed (the GCM was somewhat biased towards southerly flow in this respect). HadRM2 provides a more realistic simulation of the relationships between air flow and temperature anomaly over the UK than does HadCM2, although the representation of precipitation is not substantially improved by using the RCM run on GCM boundary conditions. The RCM also shows improvement in simulation of the frequency with which various synoptic circulation types occur over the UK in most seasons and for most air flow indices.

In a wider context, predictors other than air flow indices, such as geopotential height or specific humidity, may also be used. One way of conducting such analysis would be to choose 2 variables such as $500 \mathrm{mb}$ geopotential height and flow strength, and classify temperature anomalies or precipitation totals by the different combinations of the 2 predictor variables. However, the limited availability of data did not allow such comparisons to be made.

Overall, the research has demonstrated that, although some systematic errors and unresolved subgrid-scale processes remain, overall the results lead to increased confidence in the use of HadRM2 rather than HadCM2 in the construction of future climate change scenarios.

Acknowledgements. This study was funded under DETR Contract No. EPG 1/1/85. RCM data were provided by the Hadley Centre and Climate Impacts LINK project (DETR Contract No. EPG 1/1/68). We are grateful to Dr Xianfu Lu for technical assistance and to Dr James Murphy from the Hadley Centre for valuable comments.

\section{LITERATURE CITED}

Christensen JH, Machenhauer B, Jones RG, Schaer C, Ruti PM, Castro M, Visconti G (1997) Validation of present-day regional climate simulations over Europe: LAM simulations with observed boundary conditions. Clim Dyn 13(7-8):489-506

Conway D, Wilby RL, Jones PD (1996) Precipitation and air flow indices over the British Isles. Clim Res 7:169-183

Crane RG, Hewitson BC (1998) Doubled $\mathrm{CO}_{2}$ climate change scenarios for the Susquehanna Basin: precipitation. Int J Climatol 18:65-76

Durman CF, Gregory JM, Hassell DC, Jones RG, Murphy JM (2001) A comparison of extreme European daily precipitation simulated by a global and regional climate model for present and future climates. Q J R Meteorol Soc 127(573): 1005-1015

Editorial responsibility: Hans von Storch, Geesthacht, Germany
Giorgi F, Mearns LO (1999) Introduction to special section: regional climate modeling revisited. J Geophys Res 104(D6):6335-6352

Gregory JM, Jones PD, Wigley TML (1991) Precipitation in Britain: an analysis of area-average data updated to 1989. Int J Climatol 11:331-345

Hulme M, Jenkins GJ (1998) Climate change scenarios for the UK: scientific report. UKCIP Tech Rep No. 1, Climatic Research Unit, Norwich

Jenkinson AF, Collison FP (1977) An initial climatology of gales over the North Sea. Synoptic Climatology Branch Memorandum No. 62, Meteorological Office, Bracknell

Johns TC, Carnell RE, Crossley JF, Gregory JM, Mitchell JFB, Senior CA, Tett SFB, Wood RA (1997) The second Hadley Centre coupled ocean-atmosphere GCM: model description, spinup and validation. Clim Dyn 13:103-134

Jones PD, Hulme M, Briffa K (1993) A comparison of Lamb circulation types with an objective classification scheme. Int J Climatol 13:655-663

Jones RG, Murphy JM, Noguer M (1995) Simulation of climate change over Europe using a nested regional-climate model. I: Assessment of control climate, including sensitivity to location of lateral boundaries. Q J R Meteorol Soc 121:1413-1449

Leung LR, Ghan SJ (1999) Pacific Northwest climate sensitivity simulated by a regional climate model driven by a GCM. Part 1: Control simulations. J Clim 12(7):2010-2030

Lynch AH, Chapman WL, Walsh JE, Weller G (1995) Development of a regional climate model of the western Arctic. J Clim 8(6):1555-1570

Murphy JM (1999) An evaluation of statistical and dynamical techniques for downscaling local climate. J Clim 12: $2256-2284$

Murphy JM (2000) Predictions of climate change over Europe using statistical and dynamical downscaling techniques. Int J Climatol 20(5):489-501

Noguer M, Jones R, Murphy J (1998) Sources of systematic errors in the climatology of a regional climate model over Europe. Clim Dyn 14:691-712

Osborn TJ, Conway D, Hulme M, Gregory JM, Jones PD (1999) Air flow influences on local climate: observed and simulated mean relationships for the United Kingdom. Clim Res 13:173-191

Parker DE, Legg TP, Folland CK (1992) A new daily Central England Temperature series, 1772-1991. Int J Climatol 12: 317-342

Renwick JA, Katzfey JJ, Nguyen KC, McGregor JL (1998) Regional model simulations of New Zealand climate. J Geophys Res 103(D6):5973-5982

Rinke A, Dethloff K, Christensen JH (1999) Arctic winter climate and its interannual variations simulated by a regional climate model. J Geophys Res 104(D16): 19027-19038

Wetzel MA, Bates GT (1995) Comparison of simulated cloud cover with satellite observations. J Clim 8(2):296-314

Wilby RL, Wigley TML (1997) Downscaling general circulation model output: a review of methods and limitations. Prog Phys Geogr 21(4):530-548

Submitted: January 25, 2001; Accepted: August 29, 2001 Proofs received from author(s): February 26, 2002 